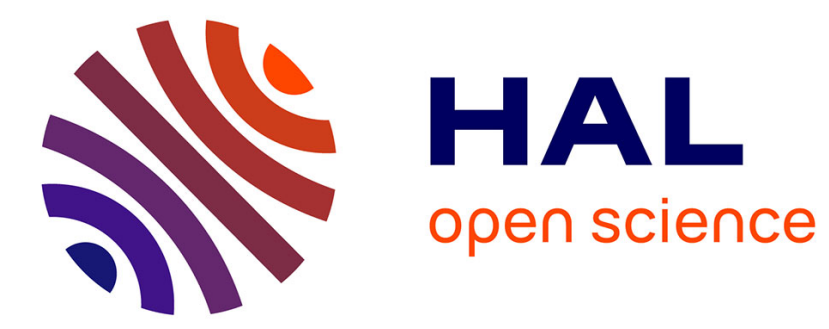

\title{
RELATING THEORY TO EXPERIMENT : THE OPTICAL PROPERTIES OF COPPER
}

\author{
A. Williams, J. Janak, V. Moruzzi
}

\section{To cite this version:}

A. Williams, J. Janak, V. Moruzzi. RELATING THEORY TO EXPERIMENT: THE OPTICAL PROPERTIES OF COPPER. Journal de Physique Colloques, 1972, 33 (C3), pp.C3-131-C3-134. 10.1051/jphyscol:1972319 . jpa-00215053

\section{HAL Id: jpa-00215053 https://hal.science/jpa-00215053}

Submitted on 1 Jan 1972

HAL is a multi-disciplinary open access archive for the deposit and dissemination of scientific research documents, whether they are published or not. The documents may come from teaching and research institutions in France or abroad, or from public or private research centers.
L'archive ouverte pluridisciplinaire HAL, est destinée au dépôt et à la diffusion de documents scientifiques de niveau recherche, publiés ou non, émanant des établissements d'enseignement et de recherche français ou étrangers, des laboratoires publics ou privés. 


\title{
RELATING THEORY TO EXPERIMENI : THE OPTICAL PROPERTIES OF COPPER (*)
}

\author{
A. R. WILLIAMS, J. F. JANAK and V. L. MORUZZI \\ IBM Thomas J. Watson Research Center Yorktown Heights, New York 10598
}

\begin{abstract}
Résumé. - On a calculé des propriétés de la surface de Fermi, l'absorption optique $\varepsilon_{2}(\omega)$ et la photoémission utilisant le potentiel de Chodorow pour le cuivre. Les éléments de matrice du moment ont été calculés. La confrontation à l'expérience indique que le potentiel de Chodorow sous-estime l'aire du col de la surface de Fermi et donne des niveaux excités qui sont trop bas, quoiqu'il soit satisfaisant pour la plupart des niveaux occupés. Le point essentiel, c'est qu'on puisse enfin faire des calculs de ce genre avec une précision interne qui permet l'application des données expérimentales à la construction du potentiel effectif.

Abstract. - Calculations of Fermi surface properties, interband absorption $\varepsilon_{2}(\omega)$ and photoemission have been performed using the Chodorow potential for copper. Momentum matrix elements have also been calculated. Comparison of these results to experiment indicates that the Chodorow potential, while adequate for most of the occupied states, underestimates the Fermi surface neck areas, and gives excited-state energies which are about $10 \%$ too low. The central point is made that such calculations can now be performed with sufficient internal accuracy to bring experimental data to bear on the formulation of the effective one-electron potential.
\end{abstract}

I. Introduction. - The calculation of the electronic properties of a solid involves several steps : (1) reduction of the many-electron problem to a one-electron problem characterized by an effective electron-ion potential; (2) calculation of the energy bands and wave functions implied by this potential ; (3) interpolation in $\mathbf{k}$-space to a mesh of points sufficiently dense to permit accurate evaluation of integrals ; and (4) integration in $\mathbf{k}$-space to obtain the properties of the material such as density of states, optical properties, charge densities (which form an input back into step 1 in a self-consistent calculation), etc.

We have been concerned with eliminating computational uncertainties in steps 2 through 4 so that the results accurately reflect the electron-ion potential initially used. Although such accurate calculations can be used to explain experimental results, it is equally important to bring experimental evidence to bear on the assumptions required to obtain the effective one-electron potential (and here it is crucial to ensure that no spurious features are introduced during the course of the calculation). An unambiguous estimate of the importance of many-body effects in solids, for example, is given by the difference between experiment and the results of reliable one-electron calculations.

II. Procedure. - We obtain the energy bands and interband momentum matrix elements by using the KKR method at 240 points on a simple cubic lattice in the irreducible wedge of the Brillouin zone. The energies and matrix elements on a fine mesh of 10 , 100 points in the irreducible wedge are then found by

(*) Supported in part by U. S. Air Force Office of Scientific Research, Office of Aerospace Research, under Contract No. F44620-70-0089. using k.p theory locally around each of the 240 points. Since the maximum distance over which one extrapolates in this technique is only $0.07(2 \pi / a)$, the usual problems [1] associated with k.p theory are greatly reduced. Finally, integrals over the Brillouin zone are performed using the Gilat-Raubenheimer [2] method on the mesh of 10,100 points. For a given effective oneelectron potential, we currently calculate the following quantities : energy bands and momentum matrix elements (to within about 0.001 ry) ; density of states $(\sim 1 \%)$ and Fermi energy (obtained to four figures using a generalization of the GR method for performing volume integrals, which eliminates the necessity of numerically integrating the density of states); Fermi surface properties (de Haas-van Alphen areas and cyclotron masses) to within about $1 \%$, obtained using our line-integral generalization [3] of the GR method; the optical absorption $\varepsilon_{2}(\omega)$ including the momentum matrix elements; and the photoemission

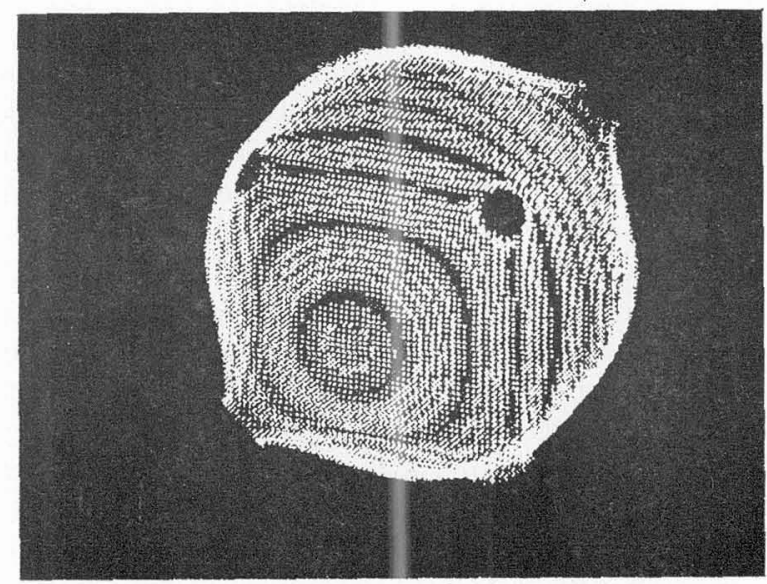

Frg. 1. - Fermi surface of silver. 
energy distributions $D(E, \omega)$, also obtained using our line-integral formulation. In addition, a graphics package automatically supplies computer-drawn $E(\mathbf{k})$ plots, and the Fermi surface can be projected onto an oscilloscope screen (Fig. 1) and studied interactively (the user can rotate the surface, measure cross-sections, etc.). We are convinced that automated visual output will become an important part of all band calculations; it eliminates a great deal of drudgery, and, more importantly, presents masses of data in a form which can be immediately absorbed by the human mind. Features (for example, programming bugs) which are otherwise buried in huge tables of numbers can be seen at a glance.

III. Results. - A high-resolution plot of the density of states in the d-bands of palladium is shown in figure 2. Structures usually shown as peaks in such plots have been resolved here, and the van Hove singularities are apparent. The density of states, however, supplies very little information about the solid, since only one number, the density of states at the Fermi energy, is experimentally accessible (and even that number involves an electron-phonon correction).

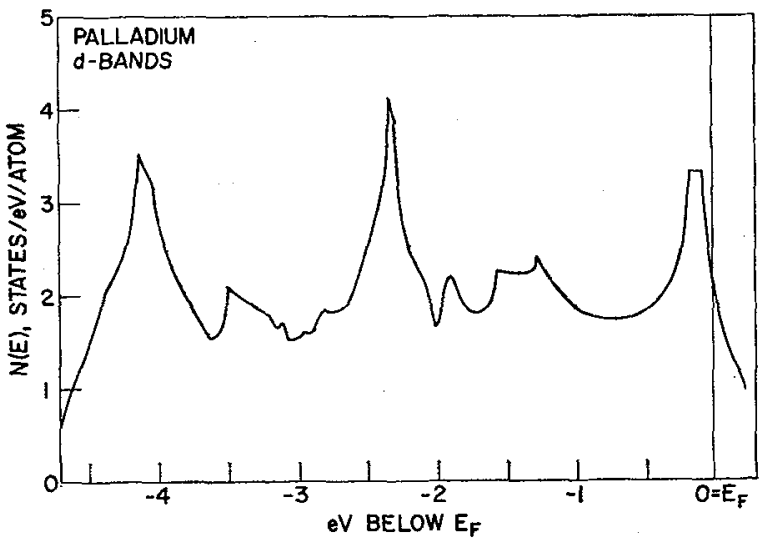

FIG. 2. - Density of states of d-bands of palladium. $N\left(E_{\mathfrak{i}}\right)=2.28$ states/eV/atom.

The best source of experimental information on the ground state is the Fermi surface, particularly the cyclotron mass (which, however, also contains an electron-phonon correction) and the de Haas-van Alphen areas (which are believed to involve no manybody corrections [4]). A comparison of our theoretical results for the Chodorow potential for copper with experimental values of these quantities for certain magnetic field directions is given in Table I. The specific heat electron-phonon correction, obtained by comparing measured [8] and theoretical values of the density of states at the Fermi energy (commonly denoted by $1+\lambda$ ) equals 1.12 ; this number may be compared to the ratio of experimental to theoretical cyclotron masses for various orbits, which gives an estimate of the anisotropy of the electron-phonon interaction (there is no reason why $\lambda$ should not be different for different orbits). It is seen that $\lambda$ varies by as much as $30 \%$ over the copper Fermi surface.

The de Haas-van Alphen frequencies afford a much better test of the potential, since they do not involve the electron-phonon interaction. The results given in Table I show that the Chodorow potential gives reasonable dimensions for the belly orbits of the copper Fermi surface, but considerably underestimates the size of the necks, a result in agreement with the calculations of Segall [5].

\section{TABLE I}

\section{Copper Fermi surface properties}

Cyclotron masses in units of free-electron mass ; de Haas-van Alphen frequencies in units of $10^{8}$ gauss. The specific heat electron-phonon correction $\left(^{(}\right)$ is 1.12 .

\section{Cyclotron Masses}

$\begin{array}{lccc}\text { Orbit } & m^{*} \text {, theory } & m^{*}, \exp \left(^{a}\right) & m_{\mathrm{ex}}^{*} / m_{\mathrm{th}}^{*} \\ \text { (100) belly } & 1.21 & 1.37 & 1.13 \\ \text { (100) rosette } & 1.22 & 1.38 & 1.13 \\ \text { (111) belly } & 1.25 & 1.385 & 1.11 \\ \text { (111) neck } & 0.402 & 0.46 & 1.14 \\ \text { (110) dogbone } & 1.12 & 1.29 & 1.16 \\ \text { (110) belly } & 1.11 & 1.225 & 1.10\end{array}$

De Haas-van Alphen Frequencies

\begin{tabular}{|c|c|c|c|}
\hline Orbit & $f$, theory & $f, \exp \left({ }^{b}\right)$ & error \\
\hline - & - & - & \\
\hline (100) belly & 5.95 & 6.0337 & $1.3 \%$ \\
\hline (100) rosette & 2.43 & 2.4751 & \\
\hline (110) dogbone & 2.49 & 2.5203 & $1.6 \%$ \\
\hline (111) belly & 5.81 & 5.8468 & $0.6 \%$ \\
\hline 11) neck & 0.210 & 0.21872 & $4 \%$ \\
\hline
\end{tabular}

$\left({ }^{a}\right)$ reference [6].

$\left({ }^{b}\right)$ reference [7].

(c) reference [8].

Some information about the excited states is contained in the optical absorption, $\varepsilon_{2}(\omega)$. Computed and experimental [9] results for copper are shown in figure 3. The theoretical $\varepsilon_{2}$ for the Chodorow potential is rather unlike the experimental result for $\hbar \omega \sim 5 \mathrm{eV}$ and has about $20 \%$ more amplitude in the peak at $5 \mathrm{eV}$. The curve shown in figure 3 was obtained by altering the d-phase shift of this potential above the Fermi energy so as to increase the $\mathrm{L}_{1}-\mathrm{L}_{2}^{\prime}$ gap from 4.6 to $4.9 \mathrm{eV}$. No other aspect of the calculation was adjusted. It appears, in other words, that the Chodorow potential leads to excited state energies for copper which are in error by as much as $10 \%$. 


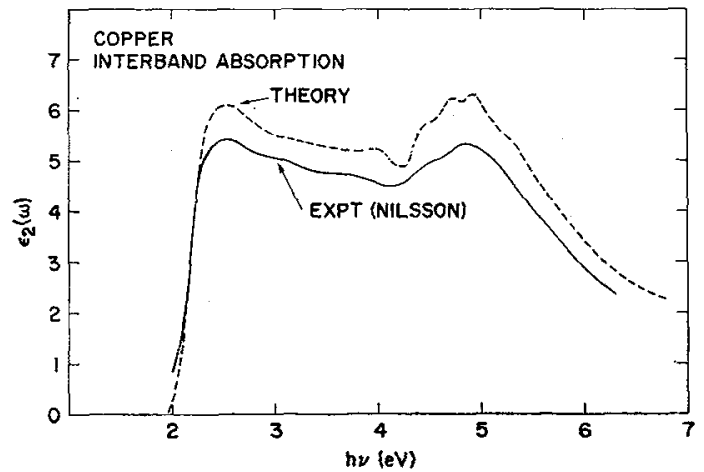

FIG. 3. -- Theoretical and experimental (ref. 9) interband absorption $\varepsilon_{2}(\omega)$ for copper.

Still more information about the excited states is contained in the photoemission experiment, which measures a function $D(\varepsilon, \omega)$ of two variables, and thus supplies an entire surface of experimental numbers. The richness of information contained in this surface is illustrated in figure 4 , which is the direct-transition theoretical result, including momentum matrix elements, following from the Chodorow potential for copper. The approximations which we use to describe the production of secondaries and transport and surface escape effects have been described elsewhere [10],

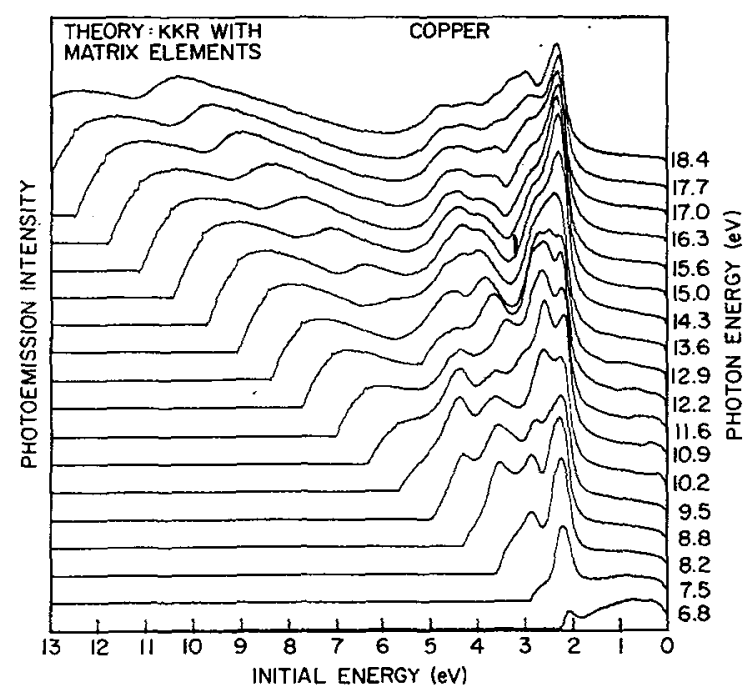

FIG. 4. - Theoretical photoemission distributions $D(E, \omega)$ for copper.

but it should be pointed out here that the left-hand portions of these curves (below an initial energy of about $-5 \mathrm{eV}$ ) are due entirely to secondary electrons. The approximations used to describe the secondaries in our calculations are inadequate, and these portions of the photoemission curves are in poor agreement with experiment. Let us therefore focus our attention on the primary electrons (the right-hand portions of the curves, above an initial energy of $-5 \mathrm{eV}$ ) and compare our results for certain photon frequencies to experiment [11] (Fig. 5). The agreement between

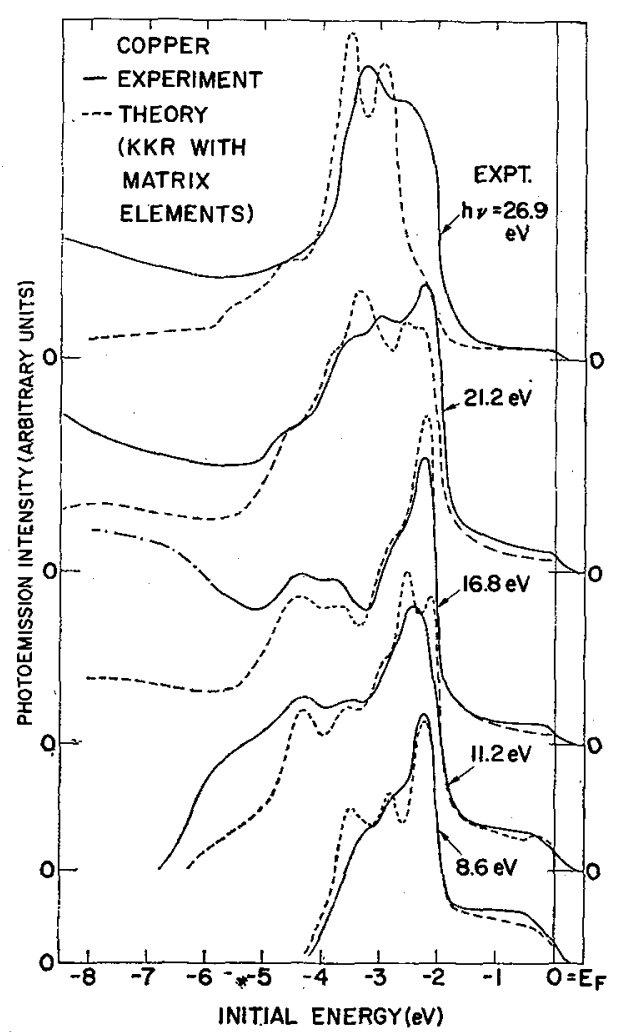

FIG. 5. - Comparison of theoretical and experimental (ref. 11) photoemission distributions for copper.

theory and experiment for photon energies below $16.8 \mathrm{eV}$ is quite good. (The theoretical curves show somewhat sharper structure than experiment, but this simply means that our theory underestimates the lifetime broadening effects. The only scattering process considered in the calculations is pair or secondary production, and, as mentioned above, our description of this process is inadequate.) Above $16.8 \mathrm{eV}$, the theory correctly predicts trends as a function of $\omega$ : a peak appears at $-4 \mathrm{eV}$ as $\omega$ increases beyond $16.8 \mathrm{eV}$, and the distribution begins to narrow when $\omega$ increases to $26.9 \mathrm{eV}$. The theory gives the correct behavior with changes in $\omega$, but the changes occur at $\omega$-values which are too low. This is just what one would expect if the excited-state energies were too low; thus the photoemission data also implies that the Chodorow potential gives incorrect excited state energies, in agreement with our analysis of $\varepsilon_{2}(\omega)$ for copper.

Acknowledgment. - We are indebted to A. Appel of IBM's Computing Systems Department, whose expertise in computer graphics made figure 1 possible. 


\section{References}

[1] Kuebing (T. J.), Schwarz (K.), Trickey (S. B.) and Conklin (J. B. Jr), Phys. Rev. Letters, 1971, 26, 1251.

[2] Gilat (G.) and Raubenheimer (L. J.), Phys. Rev., 1966, 144, 390 ; RAUBENHEIMER (L. J.) and Gilat (G.), Phys. Rev., 1967, 157, 586.

[3] J ANAK (J. F.), in Computational Methods in Band Theory, MARCUS (P. M.), JANAK (J. F.) and Williams (A. R.), ed. Plenum Press, New York, 1971, p. 323.

[4] Prange (R. E.) and Kadanoff (L. P.), Phys. Rev., 1964, 134, A 566.

[5] Segall (B.), Phys. Rev., 1962, 125, 109.
[6] Koch (J. F.), Stradling (R. A.) and KIP (A. F.), Phys. Rev., 1964, 133, A 240.

[7] Joseph (A. S.), Thorsen (A. C.), Gertner (E.) and VALBY (L. E.), Phys. Rev., 1966, 148, 569.

[8] Dixon (M.), Hoare (F. E.), Holden (T. M.) and Moody (D. E.), Proc. Roy. Soc., 1965, A 285, 561.

[9] Nilsson (P. O.), Physica Scripta, 1970, 1, 189.

[10] JANAK (J. F.), EASTMAN (D. E.) and WILLIAMS (A. R.), Sol. State Comm., 1970, 8, 271 ; Proceedings of Electronic Density of States Symposium, Gaithersburg, Md. 1969 ; NBS Spec. Publ. 323.

[11] Eastman (D. E.) and Cashon (J. K.), Phys. Rev. Letters, 1970, 24, 310. 